\section{Recurrent aborted sudden cardiac death with seizures and rhabdomyolysis due to bulimia-induced hypokalemia. Report of one case}

\author{
JOSEF FINSTERER, MD, PHD' , CLAUDIA STÖLLBERGER, MD²
}

\begin{abstract}
Recurrent vomiting due to bulimia associated with abuse of furosemide and laxatives causing severe hypokalemia may result in recurrent aborted sudden cardiac death (SCD) and seizures. We report a 25-year-old female with a history of bulimia associated with abuse of furosemide and laxatives since the age of 15 years, migraine since puberty, renal abscesses at age $20 \mathrm{y}$, and rhabdomyolysis of unknown cause at age $24 \mathrm{y}$. She experienced aborted SCD due to severe hypokalemia with symptomatic seizures at 21 and 25 years of age. Bulimia patients additionally taking laxatives or furosemide are at particular risk of SCD and rhabdomyolysis and require periodic determination of electrolytes, potassium substitution, and adequate psychiatric therapy and surveillance.
\end{abstract}

(Rev Med Chile 2014; 142: 799-802)

Key words: Bulimia; Death sudden, cardiac; Heart failure; Seizures; Ventricular fibrillation; Vomiting.

\section{Muerte súbita abortada recurrente con convulsiones y rabdomiolisis causada por hipokalemia. Informe de una paciente con bulimia}

Los vómitos recurrentes debidos a bulimia, asociados a abuso de furosemiday laxantes que causan hipokalemia severa, pueden llevar a muerte súbita abortada $y$ convulsiones. Informamos una mujer de 25 años con una historia de bulimia asociada a abuso de furosemida y laxantes desde los 15 años, migrañas desde la pubertad, abscesos renales a los 20 años y rabdomiolisis de causa desconocida a los 24 años. La paciente tuvo dos episodios de muerte súbita abortada con convulsiones a los 21 y 25 años, debido a hipokalemia severa. Los pacientes con bulimia y abuso de furosemida y laxantes tienen un riesgo mayor de tener muerte súbita y rabdomiolisis, requieren de controles periódicos de electrolitos $y$ tratamiento psiquiátrico.

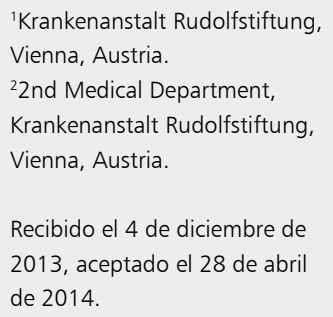

The authors have nothing to declare.

Disclosures: None.

Corresponding author: Univ. Prof. DDr. J. Finsterer Postfach 20 1180 Vienna, Austria, Europe. Tel: +43-1-71165-92085 Fax: +43-1-4781711 fifigs1@yahoo.de
Tevere hypokalemia is a life-threatening condition and associated with a number of complications ${ }^{1}$. These include QT-prolongation with induction of ventricular arrhythmias and sudden cardiac death (SCD), rhabdomyolysis with weakness and renal insufficiency, and obstipation respectively ileus ${ }^{1}$. Recurrent vomiting due to bulimia and abuse of furosemide and laxatives causing severe hypokalemia has not been reported to cause recurrent aborted SCD with symptomatic seizures so far. 


\section{Case report}

The patient is a 24 yo, Caucasian female, height $170 \mathrm{~cm}$, weight $40 \mathrm{~kg}$, who was admitted for aborted SCD due to ventricular fibrillation associated with a symptomatic, generalized tonicclonic seizure. She required cardio-pulmonary resuscitation (CPR) with defibrillation (3 times) and intubation. ECG on admission showed QTprolongation (QTc according to Bazett: $650 \mathrm{~ms}$ ) and low voltage. Blood chemical investigations revealed hypokalemia of $1.9 \mathrm{mmol} / \mathrm{L}$ ( $\mathrm{n}, 3.5-5.1$ $\mathrm{mmol} / \mathrm{L}$ ) (Table 1). The individual history was positive for recurrent palpitations at age 9 and 10 y respectively. Since age $15 \mathrm{y}$ she suffered from an eating disorder associated with habitually induced vomiting, and, according to her relatives, chronic ingestion of furosemide and laxatives. She herself denied taking furosemide or laxatives. At age $20 y$ (9/2008), she experienced left-sided nephritis with two abscess. At age 21y (8/2009), she experienced aborted SCD due to ventricular fibrillation and hypokalemia of $1.7 \mathrm{mmol} / \mathrm{l}$ also requiring CPR. Shortly after admission in $8 / 2009$, she experien- ced another episode of ventricular fibrillation, which was self-limiting and did not require CPR. Aborted SCD was complicated by heart failure, traumatic pneumothorax, pleural effusions requiring puncture, and pneumonia. Cardiac MRI was normal. One year prior to admission (age 23y), she experienced a non-triggered rhabdomyolysis resulting in acute renal failure. She also reported rare migrainous attacks since puberty.

Further diagnostic work-up revealed mild transient anemia, mild thrombopenia, moderate renal insufficiency, mildly elevated liver parameters, and hyper-CK-emia with a nadir of 4553U/l on hospital day 3 (Table 1). Quantitative urine electrolyte investigations were carried out twice. Potassium was normal twice. Sodium was reduced at the first investigation and normal at the second. Chlorides were reduced twice. During the further course ECG and most of the serum parameters normalized (Table 1). Clinical neurologic investigation revealed mild diffuse wasting but was otherwise normal. The family history was positive for subarachnoid bleeding due to an aneurysm (grandfather from the mother's side), aortic

Table 1. Blood chemical investigations during hospitalisation after the second aborted SCD

\begin{tabular}{|c|c|c|c|c|c|c|c|c|}
\hline Parameter & $\mathbf{R} \mathbf{L}$ & hd1 & hd1 & hd2 & hd3 & hd4. & hd5 & hd6 \\
\hline Thrombocytes & $150-400 \mathrm{G} / \mathrm{l}$ & nd & 206 & 154 & 119 & 119 & 114 & 145 \\
\hline Hemoglobin & $12-16 \mathrm{~g} / \mathrm{dl}$ & nd & 13 & 12.8 & 12.7 & 10.8 & 10.1 & 10.2 \\
\hline Hematocrit & $38-48 \%$ & nd & 37.1 & 35.5 & 36.3 & 32.5 & 30.5 & 30.7 \\
\hline Potassium & 3.3-5.1 mmol/L & 1.9 & 2.2 & 3.8 & nd & 5.3 & nd & nd \\
\hline Sodium & $135-150 \mathrm{mmol} / \mathrm{L}$ & 132 & 133 & 141 & nd & 143 & nd & nd \\
\hline Chloride & $98-106 \mathrm{mmol} / \mathrm{L}$ & 95 & 88 & 100 & nd & 98 & nd & nd \\
\hline Creatinine & $0.45-1.0 \mathrm{mg} / \mathrm{dl}$ & nd & 1.11 & 1.03 & 2.17 & 2.42 & 2.08 & 1.75 \\
\hline GFR & $>90 \mathrm{~mL} / \mathrm{min} / 1.73 \mathrm{~m}$ & nd & 60 & 66 & 28 & 26 & 29 & 36 \\
\hline Blood urea nitrogen & $6-20 \mathrm{mg} / \mathrm{dl}$ & nd & 10 & 21 & 30 & 39 & 40 & 31 \\
\hline CK & $26-145 U / /$ & nd & 113 & 4071 & 4552 & 3629 & 1582 & 555 \\
\hline GOT & $<36 \mathrm{U} / \mathrm{l}$ & nd & 127 & 181 & 286 & 296 & nd & 120 \\
\hline GPT & $<36 \mathrm{U} / \mathrm{L}$ & nd & 97 & 89 & 126 & 121 & 95 & 82 \\
\hline Protein & $64-83 \mathrm{~g} / \mathrm{l}$ & nd & 53 & 42 & nd & nd & nd & nd \\
\hline Lactate & $<2.1 \mathrm{mmol} / / \mathrm{l}$ & 12.4 & 4.7 & 1.6 & nd & nd & nd & nd \\
\hline Osmolarity & $275-295 \mathrm{mmol} / \mathrm{kg}$ & 273.2 & 271.9 & 271.3 & nd & nd & nd & nd \\
\hline $\mathrm{pH}$ & $7.38-7.42$ & 7.35 & 7.5 & 7.53 & nd & nd & nd & nd \\
\hline
\end{tabular}

RL: reference limits, hd: hospital day, GFR: glomerular filtration rate, CK: creatine-kinase, GOT: glutamate oxalate trasnaminase, GPT: glutamate private transaminase, nd: not determined, abnormal results are in bold. 
aneurysm (grand aunt), and coronary atherosclerosis (grandfather from the father's side). She left the hospital upon her own request and earlier than recommended with the advice to regularly substitute potassium. She was also recommended to undergo computed tomography angiography to rule out cerebral aneurysm. No antiepileptic medication was prescribed. At age 25y (11/2013), she was doing well and was under regular control of her GP.

\section{Discussion}

The presented patient is interesting for severe hypokalemia from intentious vomiting (bulimia) with abuse of furosemide or laxatives, recurrently triggering ventricular fibrillation with symptomatic seizures. She also deserves attention because clinical presentation and family history suggested a hereditary neurometabolic disease due to an oxidative defect.

The first point requiring discussion is the cause of hypokalemia. Generally, hypokalemia in the presented patient could have been induced by vomiting from bulimia, prerenal azotemia with fluid or potassium loss, rhabdomyolysis, intake of diuretics or laxatives, or hyperaldosteronism. The most likely cause, however, is bulimia, since she admitted to induce recurrent vomiting since $10 \mathrm{y}$. An argument against bulimia is that she experienced palpitations at age 9 and $10 \mathrm{y}$ respectively, possibly also induced by hypokalemia in the absence of bulimia. Arguments for the misuse of furosemide and laxatives, however, are that on admission also sodium and chloride were low (Table 1) and that electrolytes normalized during hospitalization (Table 1). Renal insufficiency as the cause of hypokalemia is rather unlikely, since it was mild and rapidly normalized during hospitalization (Table 1). Hyperaldosteronism (Conn syndrome) is also rather unlikely since she did not suffer from arterial hypertension. However, a CT scan of the suprarenal gland, adrenal iodocholesterol uptake after dexamethasone, or sampling of adrenal venous blood for aldosterone measurement, could not be carried out due to the patient's poor compliance $^{2}$. There were no indications for chronic diarrhoea, Wilson's disease ${ }^{3}$, or hyperinsulinism and no indications for excessive caffeine, cola, or glucose consumption ${ }^{4}$. Hypokalemia was most likely induced by bulimia and abuse of laxatives and furosemide.

The second point of interest is the cause of seizures. Seizures could be hereditary or symptomatic. Except for the two seizures in association with hypokalemia, no other seizures were ever reported. She never took antiepileptic drugs and the family history was negative for epilepsy. She had no head trauma and no history of complications during delivery or meningitis. Assuming that seizures were triggered, it still remains the question on which the trigger was. Hypokalemia from bulimia is rather unlikely but on admission she also presented with hyponatriemia, which is well known as a trigger of seizures. However, hyponatremia at the time of the event was only mild and hardly causative for the seizure. Only rarely seizures have been described in association with hypokalemia ${ }^{5}$. Aborted sudden unexpected death in epilepsy (SUDEP) is rather unlikely given the previous negative individual and family history for epilepsy and the fact that hypokalemia has been only rarely reported as a trigger of seizures. The most likely cause of the seizures was cerebral hypoxia during ventricular fibrillation.

A third point of interest concerning this case is the question if the patient suffered from a hereditary disease and if bulimia was a manifestation of this presumed genetic defect. Some of the clinical manifestations could have been explained by Wilson's disease, which was excluded upon absence of severe liver disease, ophthalmologic problems, and of central nervous system manifestations, particularly tremor ${ }^{3}$. However, she had a family history positive for subarachnoid bleeding from an aneurysm, aortic aneurysm, and coronary atherosclerosis. At a first glance this does not suggest hereditary disease but at a second glance a hereditary cause cannot be definitively excluded. Arguments for a metabolic disease are the history of palpitations in adolescence before the occurrence of bulimia, migraine, hepatopathy, renal insufficiency, anemia, and mild thrombocytopenia, recurrent hypokalemia, bulimia, rhabdomyolysis, and the family history positive for cerebral and aortic aneurysm. Rhabdomyolysis at age $23 y$ might be attributable to an unwitnessed seizure, severe hypokalemia, or subclinical, metabolic myopathy.

This case shows that bulimia and abuse of furosemide or laxatives may cause recurrent aborted SCD with symptomatic seizures and rhabdomyo- 
lysis. Bulimia patients additionally taking laxatives or furosemide are at particular risk of SCD and rhabdomyolysis and require periodic determination of electrolytes, and adequate psychiatric therapy and surveillance.

\section{References}

1. Halperin, ML, Kamel KS. Potassium. Lancet 1998; 352: 135-40.

2. Wémeau JL, Mounier-Vehier C, Carnaille B, Douillard
C. Primary hyperaldosteronisms: from diagnosis to treatment. Presse Med 2009; 38: 633-42.

3. Ghosh L, Shah M, Pate S, Mannari J, Sharma K. Wilson's disease presenting with hypokalemia, hypoparathyroidism and renal failure. J Assoc Physicians India 2012; 60: 57-9.

4. Tsimihodimos V, Kakaidi V, Elisaf M. Cola-induced hypokalemia: pathophysiological mechanisms and clinical implications. Int J Clin Pract 2009; 63: 900-2.

5. Wang LC, Lee WT, Tsai WY, Tsau YK, Shen YZ. Mitochondrial cytopathy combined with Fanconi's syndrome. Pediatr Neurol 2000; 22: 403-6. 